\title{
LEVELS OF MASS EXTINCTION OF PLANTS IN THE NEOGENE OF WESTERN GEORGIA
}

SHATILOVA, Irina I., Institute of Paleobiology, Georgian Academy of Sciences, 380007, Potochnaia 4, Tbilisi, Georgia

At present Western Georgia or Colchis is an isolated botanical province. It was formed in Late Sarmatian when huge orogenetic movements took place on the territory of the Caucasus entailing significant paleogeographic changes. They stimulated the processes which can be clearly traced in the history of the vegetation of Western Georgia during the Late Miocene: the extinction of most thermophyllous elements of flora that along with the change of the environment lost their competitive capacity in the struggle for the existence with more plastic plants of warm temperate and temperate climate, which were better adapted to grow in the condition of mountainous relief with differentiated climatic zones. Notwithstanding the slowing down of this process, caused by isolated position of Colchis, during the Neogene three stages of mass extinction of plants can be distinguished. The end of the Sarmatian (9,6 m.y.), the end of the Pontian (5,6 m.y.), the ent of the Kimmerian ( 3,1 m.y.). On the whole from the end of the Middle Sarmatian to the end of the Kimmerian about 350 elements of flora were extinguished, primarily subtropical plants, forming the landscapes of plains and lower mountain zones. After that on the territory of Western Georgia dominate rich warm-temperate flora. By the end of the Gurian (0,7 m.y.) the main mass of this complex extinguished and plants of temperate climate - in whose composition during the whole Pleistocene the relics of Pliocene floras were preserved - became predominant.

"The research described in this publication was made possible in part by Grant N MXJ200 from the International Science Foundation" 